\title{
THE BATTERED-CHILD SYNDROME
}

\author{
C. Henry Kempe, M.D., Denver, Frederic N. Silverman, M.D., \\ Cincinnati, Brandt F. Steele, M.D., William Droegemueller, M.D., \\ AND Henry K. Silver, M.D., Denver
}

Professor and Chairman (Dr. Kempe) and Professor of Pediatrics (Dr. Silver), Department of Pediatrics; Associate Professor of Psychiatry (Dr. Steele), and Assistant Resident in Obstetrics and Gynecology (Dr. Droegemueller), University of Colorado School of Medicine; and Director, Division of Roentgenology, Children's Hospital (Dr. Silverman).

\begin{abstract}
The battered-child syndrome, a clinical condition in young children who have received serious physical abuse, is a frequent cause of permanent injury or death. The syndrome should be considered in any child exhibiting evidence of fracture of any bone, subdural hematoma, failure to thrive, soft tissue swellings or skin bruising, in any child who dies suddenly, or where the degree and type of injury is at variance with the history given regarding the occurrence of the trauma. Psychiatric factors are probably of prime importance in the pathogenesis of the disorder, but knowledge of these factors is limited. Physicians have a duty and responsibility to the child to require a full evaluation of the problem and to guarantee that no expected repetition of trauma will be permitted to occur.
\end{abstract}

THE BATTERED-CHILD SYNDROME is a term used by us to characterize a clinical condition in young children who have received serious physical abuse, generally from a parent or foster parent. The condition has also been described as "unrecognized trauma" by radiologists, orthopedists, pediatricians, and social service workers. It is a significant cause of childhood disability and death. Unfortunately, it is frequently not recognized or, if diagnosed, is inadequately handled by the physician because of hesitation to bring the case to the attention of the proper authorities.

\section{INCIDENCE}

In an attempt to collect data from the incidence of this problem, we undertook a nationwide survey of hospitals which were asked to indicate the incidence of this syndrome in a oneyear period. Among 71 hospitals replying, 302 such cases were reported to have occurred; 33 of the children died; and 85 suffered permanent brain injury. In one-third of the cases proper medical diagnosis was followed by some type of legal action. We also surveyed 77 District Attorneys who reported that they had knowledge of 447 cases in a similar one-year period. Of these, 45 died, and 29 suffered permanent brain damage; court action was initiated in $46 \%$ of this group. This condition has been a particularly common problem in our hospitals; on a single day, in November, 1961, the Pediatric Service of the Colorado General Hospital was caring for 4 infants suffering from the parent-inflicted battered-child syndrome. Two of the 4 died of their central nervous system trauma; 1 subsequently died suddenly in an unexplained manner 4 weeks after discharge from the hospital while under the care of its parents, while the fourth is still enjoying good health.

Reprinted with permission of the American Medical Association. Landmark article first published in Journal of the American Medical Association 181:17-24, July 7, 1962, and republished in Journal of the American Medical Association 251:3288. June 22. 1984. Copyright 1962, American Medical Association. 


\section{CLINICAL MANIFESTATIONS}

The clinical manifestations of the battered-child syndrome vary widely from those cases in which the trauma is very mild and is often unsuspected and unrecognized. to those who exhibit the most florid evidence of injury to the soft tissues and skeleton. In the former group. the patients' signs and symptoms may be considered to have resulted from failure to thrive from some other cause or to have been produced by a metabolic disorder, an infectious process, or some other disturbance. In these patients specific findings of trauma such as bruises or characteristic roentgenographic changes as described below may be misinterpreted and their significance not recognized.

The battered-child syndrome may occur at any age, but, in general, the affected children are younger than 3 years. In some instances the clinical manifestations are limited to those resulting from a single episode of trauma, but more often the child's general health is below par, and he shows evidence of neglect including poor skin hygiene, multiple soft tissue injuries, and malnutrition. One often obtains a history of previous episodes suggestive of parental neglect or trauma. A marked discrepancy between clinical findings and historical data as supplied by the parents is a major diagnostic feature of the battered-child syndrome. The fact that no new lesions, either of the soft tissue or of the bone, occur while the child is in the hospital or in a protected environment lends added weight to the diagnosis and tends to exclude many diseases of the skeletal or hemopoietic systems in which lesions may occur spontaneously or after minor trauma. Subdural hematoma, with or without fracture of the skull, is, in our experience, an extremely frequent finding even in the absence of fractures of the long bones. In an occasional case the parent or parent-substitute may also have assaulted the child by administering an overdose of a drug or by exposing the child to natural gas or other toxic substances. The characteristic distribution of these multiple fractures and the observation that the lesions are in different stages of healing are of additional value in making the diagnosis.

In most instances, the diagnostic bone lesions are observed incidental to examination for purposes other than evaluation for possible abuse. Occasionally, examination following known injury discloses signs of other, unsuspected, skeletal involvement. When parental assault is under consideration, radiologic examination of the entire skeleton may provide objective confirmation. Following diagnosis, radiologic examination can document the healing of lesions and reveal the appearance of new lesions if additional trauma has been inflicted.

The radiologic manifestations of trauma to growing skeletal structures are the same whether or not there is a history of injury. Yet there is reluctance on the part of many physicians to accept the radiologic signs as indications of repetitive trauma and possible abuse. This reluctance stems from the emotional unwillingness of the physician to consider abuse as the cause of the child's difficulty and also because of unfamiliarity with certain aspects of fracture healing so that he is unsure of the significance of the lesions that are present. To the informed physician, the bones tell a story the child is too young or too frightened to tell.

\section{PSYCHIATRIC ASPECTS}

Psychiatric knowledge pertaining to the problem of the battered child is meager and the literature on the subject is almost nonexistent. The type and degree of physical attack varies greatly. At one extreme, there is direct murder of children. This is usually done by a parent or other close relative, and, in these individuals, a frank psychosis is usually readily apparent. At the other extreme are those cases where no overt harm has occurred, and one parent, more often the mother, comes to the psychiatrist for help, filled with anxiety and guilt related to 
fantasies of hurting the child. Occasionally the disorder has gone beyond the point of fantasy and has resulted in severe slapping or spanking. In such cases the adult is usually responsive to treatment; it is not known whether or not the disturbance in these adults would progress to the point where they would inflict significant trauma on the child.

Between these 2 extremes are a large number of battered children with mild to severe injury which may clear completely or result in permanent damage or even death after repeated attack. Descriptions of such children have been published by numerous investigators including radiologists, orthopedists, and social workers. The latter have reported on their studies of investigations of families in which children have been beaten and of their work in effecting satisfactory placement for the protection of the child. In some of these published reports, the parents, or at least the parent who inflicted the abuse, have been found to be of low intelligence. Often, they are described as psychopathic or sociopathic characters. Alcoholism, sexual promiscuity, unstable marriages, and minor criminal activities are reportedly common amongst them. They are immature, impulsive, self-centered, hypersensitive, and quick to react with poorly controlled aggression. Data in some cases indicate that such attacking parents had themselves been subject to some degree of attack from their parents in their own childhood.

Beating of children, however, is not confined to people with a psychopathic personality or of borderline socioeconomic status. It also occurs among people with good education and stable financial and social background. However, from the scant data that are available, it would appear that in these cases, too, there is a defect in character structure which allows aggressive impulses to be expressed too freely. There is also some suggestion that the attacking parent was subjected to similar abuse in childhood. It would appear that one of the most important factors to be found in families where parental assault occurs is "to do unto others as you have been done by." This is not surprising; it has long been recognized by psychologists and social anthropologists that patterns of child rearing, both good and bad, are passed from one generation to the next in relatively unchanged form. Psychologically, one could describe this phenomenon as an identification with the aggressive parent, this identification occurring despite strong wishes of the person to be different. Not infrequently the beaten infant is a product of an unwanted pregnancy, a pregnancy which began before marriage, too soon after marriage, or at some other time felt to be extremely inconvenient. Sometimes several children in one family have been beaten; at other times one child is singled out for attack while others are treated quite lovingly. We have also seen instances in which the sex of the child who is severely attacked is related to very specific factors in the context of the abusive parent's neurosis.

It is often difficult to obtain the information that a child has been attacked by its parent. To be sure, some of the extremely sociopathic characters will say, "Yeah, Johnny would not stop crying so I hit him. So what? He cried harder so I hit him harder." Sometimes one spouse will indicate that the other was the attacking person, but more often there is complete denial of any knowledge of injury to the child and the maintenance of an attitude of complete innocence on the part of both parents. Such attitudes are maintained despite the fact that evidence of physical attack is obvious and that the trauma could not have happened in any other way. Denial by the parents of any involvement in the abusive episode may, at times, be a conscious, protective device, but in other instances it may be a denial based upon psychological repression. Thus, one mother who seemed to have been the one who injured her baby had complete amnesia for the episodes in which her aggression burst forth so strikingly.

In addition to the reluctance of the parents to give information regarding the attacks on their children, there is another factor which is of great importance and extreme interest as it relates to the difficulty in delving into the problem of parental neglect and abuse. This is the fact that physicians have great difficulty both in believing that parents could have attacked their children and in undertaking the essential questioning of parents on this subject. Many 
physicians find it hard to believe that such an attack could have occurred and they attempt to obliterate such suspicions from their minds, even in the face of obvious circumstantial evidence. The reasons for this is not clearly understood. One possibility is that the arousal of the physician's antipathy in response to such situations is so great that it is easier for the physician to deny the possibility of such attack than to have to deal with the excessive anger which surges up in him when he realizes the truth of the situation. Furthermore, the physician's training and personality usually makes it quite difficult for him to assume the role of policeman or district attorney and start questioning parents as if he were investigating a crime. The humanitarian-minded physician finds it most difficult to proceed when he is met with protestations of innocence from the aggressive parent, especially when the hattered child was brought to him voluntarily.

Although the technique wherein the physician obtains the necessary information in cases of child beating is not adequately solved, certain routes of questioning have been particularly fruitful in some cases. One spouse may be asked about the other spouse in relation to unusual or curious behavior or for direct description of dealings with the baby. Clues to the parents' character and pattern of response may be obtained by asking questions about sources of worry and tension. Revealing answers may be brought out by questions concerning the baby such as, "Does he cry a lot? Is he stubborn? Does he obey well? Does he eat well? Do you have problems in controlling him?" A few general questions concerning the parents' own ideas of how they themselves were brought up may bring forth illuminating answers; interviews with grandparents or other relatives may elicit additional suggestive data. In some cases, psychological tests may disclose strong aggressive tendencies, impulsive behavior, and lack of adequate mechanisms of controlling impulsive behavior. In other cases only prolonged contact in a psychotherapeutic milieu will lead to a complete understanding of the background and circumstances surrounding the parental attack. Observation by nurses or other ancillary personnel of the behavior of the parents in relation to the hospitalized infant is often extremely valuable.

The following 2 condensed case histories depict some of the problems encountered in dealing with the battered-child syndrome.

\section{REPORT OF CASES}

CASE 1.-The patient was brought to the hospital at the age of 3 months because of enlargement of the head, convulsions, and spells of unconsciousness. Examination revcaled bilateral subdural hematomas, which were later operated upon with great improvement in physical status. There had been a hospital admission at the age of one month because of a fracture of the right femur, sustained "when the baby turned over in the crib and caught its leg in the slats." There was no history of any head trauma except "when the baby was in the other hospital a child threw a little toy at her and hit her in the head." The father had never been alone with the baby, and the symptoms of difficulty appeared to have begun when the mother had been caring for the baby. Both parents showed concern and requested the best possible care for their infant. The father, a graduate engineer, related instances of impulsive behavior, but these did not appear to be particularly abnormal, and he showed appropriate emotional concern over the baby's appearance and impending operation. The mother, aged 21, a high school graduate, was very warm. friendly, and gave all the appearance of having endeavored to be a good mother. However, it was noted by both nurses and physicians that she did not react as appropriately or seem as upset about the baby's appearance as did her husband. From interviews with the father and later with the mother, it became apparent that she had occasionally shown very impulsive, angry behavior, sometimes acting rather strangely and doing bizarre things which she could not explain nor remember. This was their first child and had resulted from an unwanted pregnancy which had occurred almost immediately after marriage and before the parents were ready for it. Early in pregnancy the mother had made statements about giving the baby away, but by the time of delivery she was apparently delighted with the baby and seemed to be quite fond of it. After many interviews, it became apparent that the mother had identified herself with her own mother who had also been unhappy with her first pregnancy and had frequently beaten her children. Despite very strong conscious wishes to be a kind, good mother, the mother of our patient was evidently repeating the behavior of her own mother toward herself. Although an admission of guilt was not obtained. it seemed 
likely that the mother was the one responsible for attacking the child; only after several months of treatment did the amnesia for the aggressive outbursts begin to lift. She responded well to treatment, but for a prolonged period after the infant left the hospital the mother was not allowed alone with her.

CASE 2.-This patient was admitted to the hospital at the age of 13 months with signs of central nervous system damage and was found to have a fractured skull. The parents were questioned closely, but no history of trauma could be elicited. After one week in the hospital no further treatment was deemed necessary, so the infant was discharged home in the care of her mother, only to return a few hours later with hemiparesis, a defect in vision, and a new depressed skull fracture on the other side of the head. There was no satisfactory explanation for the new skull fracture, but the mother denied having been involved in causing the injury, even though the history revealed that the child had changed markedly during the hour when the mother had been alone with her. The parents of this child were a young, middle-class couple who, in less than 2 years of marriage, had been separated, divorced, and remarried. Both felt that the infant had been unwanted and had come too soon in the marriage. The mother gave a history of having had a "nervous breakdown" during her teens. She had received psychiatric assistance because she had been markedly upset early in the pregnancy. Following an uneventful delivery, she had been depressed and had received further psychiatric aid and 4 electroshock treatments. The mother tended to gloss over the unhappiness during the pregnancy and stated that she was quite delighted when the baby was born. It is interesting to note that the baby's first symptoms of difficulty began the first day after its first birthday, suggesting an "anniversary reaction." On psychological and neurological examination, this mother showed definite signs of organic brain damage probably of lifelong duration and possibly related to her own prematurity. Apparently her significant intellectual defects had been camouflaged by an attitude of coy, naive, cooperative sweetness which distracted attention from her deficits. It was noteworthy that she had managed to complete a year of college work despite a borderine I.Q. It appeared that the impairment in mental functioning was probably the prime factor associated with poor control of aggressive impulses. It is known that some individuals may react with aggressive attack or psychosis when faced with demands beyond their intellectual capacity. This mother was not allowed to have unsupervised care of her child.

Up to the present time, therapeutic experience with the parents of battered children is minimal. Counseling carried on in social agencies has been far from successful or rewarding. We know of no reports of successful psychotherapy in such cases. In general, psychiatrists feel that treatment of the so-called psychopath or sociopath is rarely successful. Further psychological investigation of the character structure of attacking parents is sorely needed. Hopefully, better understanding of the mechanisms involved in the control and release of aggressive impulses will aid in the earlier diagnosis, prevention of attack, and treatment of parents, as well as give us better ability to predict the likelihood of further attack in the future. At present, there is no safe remedy in the situation except the separation of battered children from their insufficiently protective parents.

\section{TECHNIQUES OF EVALUATION}

A physician needs to have a high initial level of suspicion of the diagnosis of the batteredchild syndrome in instances of subdural hematoma, multiple unexplained fractures at different stages of healing, failure to thrive, when soft tissue swellings or skin bruising are present, or in any other situation where the degree and type of injury is at variance with the history given regarding its occurrence or in any child who dies suddenly. Where the problem of parental abuse comes up for consideration, the physician should tell the parents that it is his opinion that the injury should not occur if the child were adequately protected, and he should indicate that he would welcome the parents giving him the full story so that he might be able to give greater assistance to them to prevent similar occurrences from taking place in the future. The idea that they can now help the child by giving a very complete history of circumstances surrounding the injury sometimes helps the parents feel they are atoning for the wrong that they have done. But in many instances, regardless of the approach used in attempting to elicit a full story of the abusive incident(s), the parents will continue to deny that they were guilty of any wrongdoing. In talking with the parents, the physician may sometimes obtain added information by showing that he understands their problem and that 

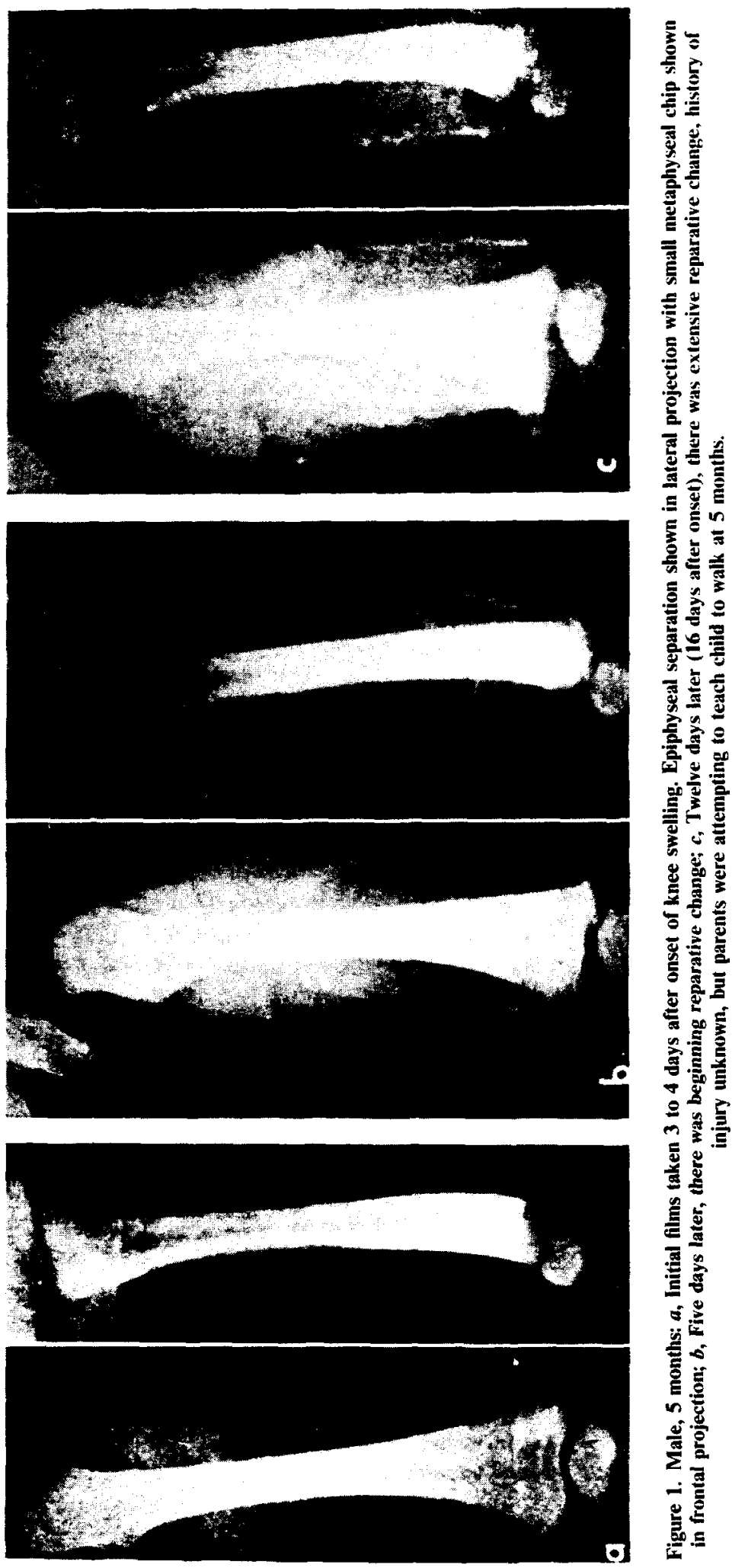


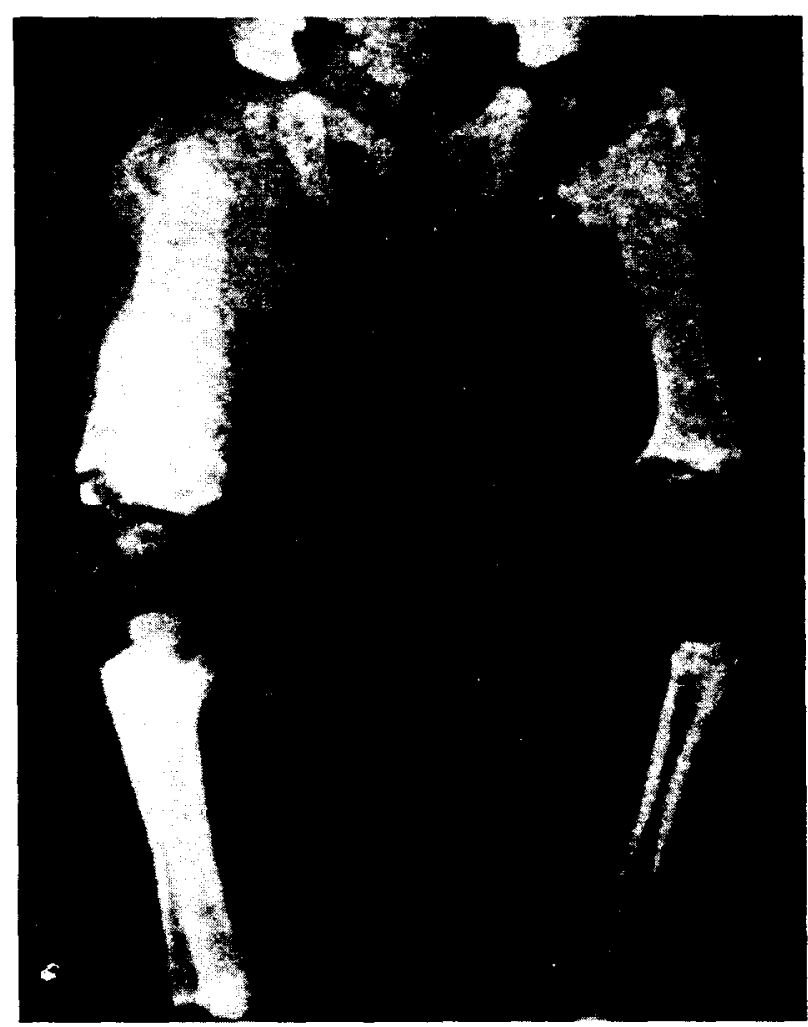

Figure 2. Female, $71 / 2$ months with a history of recurring abuse, including being shaken while held by legs 4-6 weeks prior to film. Note recent (2-3 weeks) metaphyseal fragmentation, older (4-6 weeks) periosteal reaction, and remote (2-4 months) external cortical thickening. Note also normal osseous structure of uninjured pelvic bones. (By permission of Amer $J$ Roentgenol.)

he wishes to be of aid to them as well as to the child. He may help them reveal the circumstances of the injuries by pointing out reasons that they may use to explain their action. If it is suggested that "new parents sometimes lose their tempers and are a little too forceful in their actions," the parents may grasp such a statement as the excuse for their actions. Interrogation should not be angry or hostile but should be sympathetic and quiet with the physician indicating his assurance that the diagnosis is well established on the basis of objective findings and that all parties, including the parents, have an obligation to avoid a repetition of the circumstances leading to the trauma. The doctor should recognize that bringing the child for medical attention in itself does not necessarily indicate that the parents were innocent of wrongdoing and are showing proper concern; trauma may have been inflicted during times of uncontrollable temporary rage. Regardless of the physician's personal reluctance to become involved, complete investigation is necessary for the child's protection so that a decision can be made as to the necessity of placing the child away from the parents until matters are fully clarified.

Often, the guilty parent is the one who gives the impression of being the more normal. In 2 recent instances young physicians have assumed that the mother was at fault because she was unkempt and depressed while the father, in each case a military man with good grooming and polite manners. turned out to be the psychopathic member of the family. In these instances it became apparent that the mother had good reason to be depressed.

\section{RADIOLOGIC FEATURES}

Radiologic examination plays 2 main roles in the problem of child abuse. Initially, it is a tool for case finding, and, subsequently, it is useful as a guide in management. 


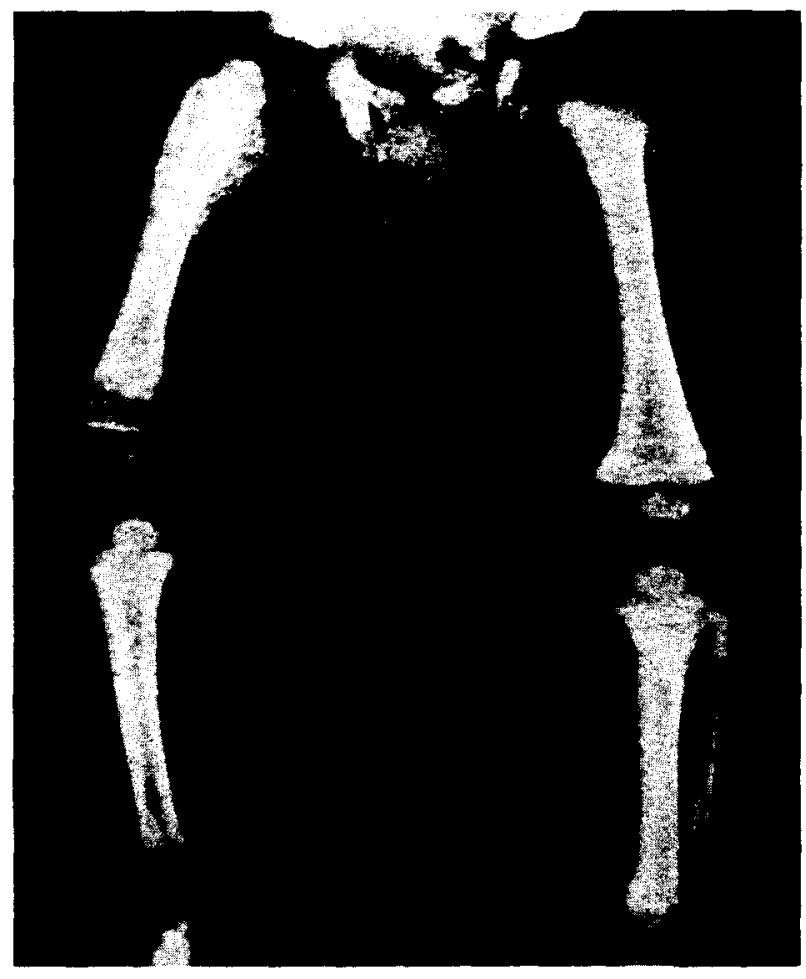

Figure 3. Male, 5 months, pulled by legs from collapsing bathinette 6 weeks earlier. Epiphyseal separation, right hip, shown by position of capital ossification center. Healing subperiosteal bematoma adjacent to it. Healing metaphyseal lesions in left knee, healing periosteal reactions (mild) in left tibia. No signs of systemic disease. (By permission of Amer $J$ Roentgenol.)

The diagnostic signs result from a combination of circumstances: age of the patient, nature of the injury, the time that has elapsed before the examination is carried out, and whether the traumatic episode was repeated or occurred only once.

Age

As a general rule, the children are under 3 years of age; most, in fact are infants. In this age group the relative amount of radiolucent cartilage is great; therefore, anatomical disruptions of cartilage without gross deformity are radiologically invisible or difficult to demonstrate (Fig. 1a). Since the periosteum of infants is less securely attached to the underlying bone than in older children and adults, it is more easily and extensively stripped from the shaft by hemorrhage than in older patients. In infancy massive subperiosteal hematomas may follow injury and elevate the active periosteum so that new bone formation can take place around and remote-from the parent shaft (Figs. $1 \mathrm{c}$ and 2).

\section{Nature of Injury}

The ease and frequency with which a child is seized by his arms or legs make injuries to the appendicular skeleton the most common in this syndrome. Even when bony injuries are present elsewhere, e.g., skull, spine, or ribs, signs of injuries to the extremities are usually present. The extremities are the "handles" for rough handling, whether the arm is pulled to bring a reluctant child to his feet or to speed his ascent upstairs or whether the legs are held while swinging the tiny body in a punitive way or in an attempt to enforce corrective measures. The forces applied by an adult hand in grasping and seizing usually involve traction 

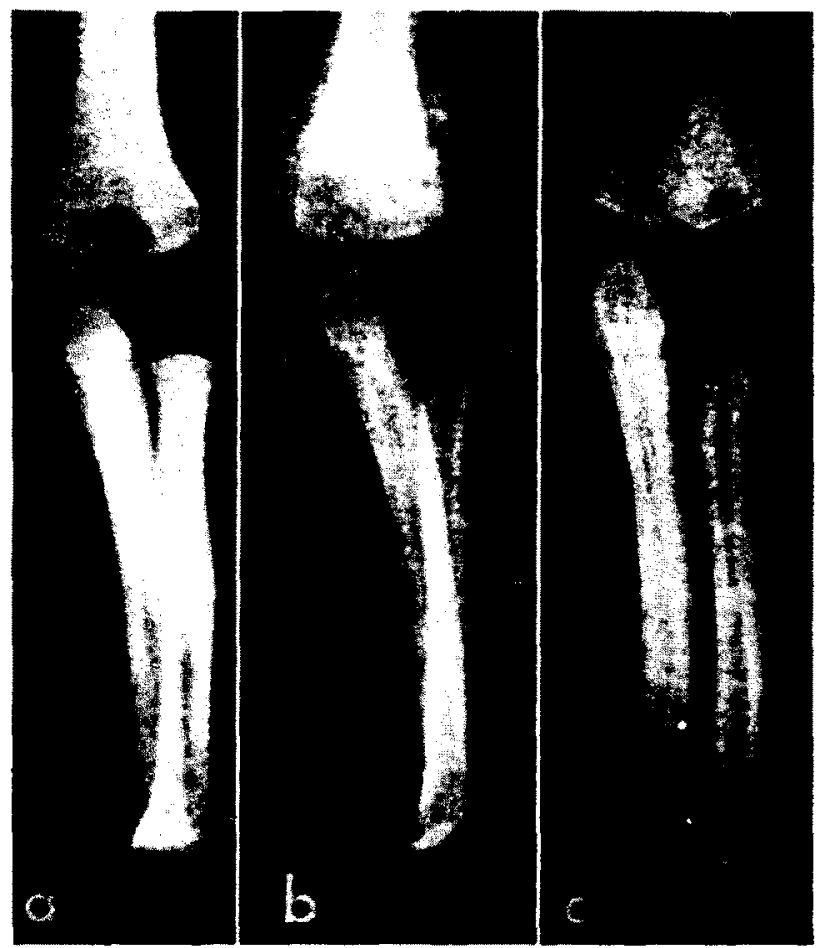

Figure 4. Female $7 / 2$ months: $a$, Dlbow injured 30 bours before, except for thickened cortex from previous healed reactions, no radiologic signs of injury; $b$, Fifteen days after injury, irregular productive reaction, clinically normal joint; $c$, Three weeks after $b$, organization and healing progressing nicely. (By permission of Amer I Roentgenol.)

and torsion; these are the forces most likely to produce epiphyseal separation and periosteal shearing (Figs. 1 and 3). Shaft fractures result from direct blows or from bending and compression forces.

Time After Injury that the X-Ray Examination is Made

This is important in evaluating known or suspected cases of child abuse. Unless gross fractures, dislocations, or epiphyseal separations were produced, no signs of bone injury are found during the first week after a specific injury. Reparative changes may first become manifest about 12 to 14 days after the injury and can increase over the subsequent weeks depending on the extent of initial injury and the degree of repetition (Fig. 4). Reparative changes are more active in the growing bones of children than in adults and are reflected radiologically in the excessive new bone reaction. Histologically, the reaction has been confused with neoplastic change by those unfamiliar with the vigorous reactions of young growing tissue.

\section{Repetition of Injury}

This is probably the most important factor in producing diagnostic radiologic signs of the syndrome. The findings may depend on diminished immobilization of an injured bone lead- 
ing to recurring macro- and microtrauma in the area of injury and healing, with accompanying excessive local reaction and hemorrhage, and ultimately, exaggerated repair. Secondly, repetitive injury may produce bone lesions in one area at one time, and in another area at another, producing lesions in several areas and in different stages of healing (Fig. 3).

Thus, the classical radiologic features of the battered-child syndrome are usually found in the appendicular skeleton in very young children. There may be irregularities of mineralization in the metaphyses of some of the major tubular bones with slight malalignment of the adjacent epiphyseal ossification center. An overt fracture may be present in another bone. Elsewhere, there may be abundant and active but well-calcified subperiosteal reaction with widening from the shaft toward one end of the bone. One or more bones may demonstrate distinctly thickened cortices, residuals of previously healed periosteal reactions. In addition, the radiographic features of a subdural hematoma with or without obvious skull fracture may be present.

\section{Differential Diagnosis}

The radiologic features are so distinct that other diseases generally are considered only because of the reluctance to accept the implications of the bony lesions. Unless certain aspects of bone healing are considered, the pertinent findings may be missed. In many cases roentgenographic examination is only undertaken soon after known injury; if a fracture is found, reexamination is done after reduction and immobilization; and, if satisfactory positioning has been obtained, the next examination is usually not carried out for a period of 6 weeks when the cast is removed. Any interval films that may have been taken prior to this time probably would have been unsatisfactory since the fine details of the bony lesions would have been obscured by the cast. If fragmentation and bone production are seen, they are considered to be evidence of repair rather than manifestations of multiple or repetitive trauma. If obvious fracture or the knowledge of injury is absent, the bony changes may be considered to be the result of scurvy, syphilis, infantile cortical hyperostoses, or other conditions. The distribution of lesions in the abused child is unrelated to rates of growth; moreover, an extensive lesion may be present at the slow-growing end of a bone which otherwise is normally mineralized and shows no evidence of metabolic disorder at its rapidly growing end.

Scurvy is commonly suggested as an alternative diagnosis, since it also produces large calcifying subperiosteal hemorrhages due to trauma and local exaggerations most marked in areas of rapid growth. However, scurvy is a systemic disease in which all of the bones show the generalized osteoporosis associated with the disease. The dietary histories of most children with recognized trauma have not been grossly abnormal and whenever the vitamin $\mathrm{C}$ content of the blood has been determined, it has been normal.

In the first months of life syphilis can result in metaphyseal and periosteal lesions similar to those under discussion. However, the bone lesions of syphilis tend to be symmetrical and are usually accompanied by other stigmata of the disease. Serological tests should be obtained in questionable cases.

Osteogenesis imperfecta also has bony changes which may be confused with those due to trauma, but it too is a generalized disease, and evidence of the disorder should be present in the bones which are not involved in the disruptive-productive reaction. Even when skull fractures are present, the mosaic ossification pattern of the cranial vault, characteristic of osteogenesis imperfecta, is not seen in the battered-child syndrome. Fractures in osteogenesis imperfecta are commonly of the shafts; they usually occur in the metaphyseal regions in the battered-child syndrome. Blue sclerae, skeletal deformities, and a family history of similar abnormalities were absent in reported instances of children with unrecognized trauma. 
Productive diaphyseal lesions may occur in infantile cortical hyperostosis, but the metaphyseal lesions of unrecognized trauma easily serve to differentiate the 2 conditions. The characteristic mandibular involvement of infantile cortical hyperostosis does not occur following trauma although obvious mandibular fracture may be produced.

Evidence that repetitive unrecognized trauma is the cause of the bony changes found in the battered-child syndrome is, in part, derived from the finding that similar roentgenographic findings are present in paraplegic patients with sensory deficit and in patients with congenital indifference to pain; in both of whom similar pathogenic mechanisms operate. In paraplegic children unappreciated injuries have resulted in radiologic pictures with irregular metaphyseal rarefactions, exaggerated subperiosteal new bone formation, and ultimate healing with residual external cortical thickening comparable to those in the battered-child syndrome. In paraplegic adults, excessive callus may form as a consequence of the lack of immobilization, and the lesion may be erroneously diagnosed as osteogenic sarcoma. In children with congenital indifference (or insensitivity) to pain, identical radiologic manifestations may be found.

To summarize, the radiologic manifestations of trauma are specific, and the metaphyseal lesions in particular occur in no other disease of which we are aware. The findings permit a radiologic diagnosis even when the clinical history seems to refute the possibility of trauma. Under such circumstances, the history must be reviewed, and the child's environment, carefully investigated.

\section{MANAGEMENT}

The principal concern of the physician should be to make the correct diagnosis so that he can institute proper therapy and make certain that a similar event will not occur again. $\mathrm{He}$ should report possible willful trauma to the police department or any special children's protective service that operates in his community. The report that he makes should be restricted to the objective findings which can be verified and, where possible, should be supported by photographs and roentgenograms. For hospitalized patients, the hospital director and the social service department should be notified. In many states the hospital is also required to report any case of possible unexplained injury to the proper authorities. The physician should acquaint himself with the facilities available in private and public agencies that provide protective services for children. These include children's humane societies, divisions of welfare departments, and societies for the prevention of cruelty to children. These, as well as the police department, maintain a close association with the juvenile court. Any of these agencies may be of assistance in bringing the case before the court which alone has the legal power to sustain a dependency petition for temporary or permanent separation of the child from the parents' custody. In addition to the legal investigation, it is usually helpful to have an evaluation of the psychological and social factors in the case; this should be started while the child is still in the hospital. If necessary, a court order should be obtained so that such investigation may be performed.

In many instances the prompt return of the child to the home is contraindicated because of the threat that additional trauma offers to the child's health and life. Temporary placement with relatives or in a well-supervised foster home is often indicated in order to prevent further tragic injury or death to a child who is returned too soon to the original dangerous environment. All too often, despite the apparent cooperativeness of the parents and their apparent desire to have the child with them, the child returns to his home only to be assaulted again and suffer permanent brain damage or death. Therefore, the bias should be in favor of the child's safety; everything should be done to prevent repeated trauma, and the physician should not be satisfied to return the child to an environment where even a moderate risk of repetition exists. 


\section{SUMMARY}

The battered-child syndrome, a clinical condition in young children who have received serious physical abuse, is a frequent cause of permanent injury or death. Although the findings are quite variable, the syndrome should be considered in any child exhibiting evidence of possible trauma or neglect (fracture of any bone, subdural hematoma, multiple soft tissue injuries, poor skin hygiene, or malnutrition) or where there is a marked discrepancy between the clinical findings and the historical data as supplied by the parents. In cases where a history of specific injury is not available, or in any child who dies suddenly, roentgenograms of the entire skeleton should still be obtained in order to ascertain the presence of characteristic multiple bony lesions in various stages of healing.

Psychiatric factors are probably of prime importance in the pathogenesis of the disorder, but our knowledge of these factors is limited. Parents who inflict abuse on their children do not necessarily have psychopathic or sociopathic personalities or come from borderline socioeconomic groups, although most published cases have been in these categories. In most cases some defect in character structure is probably present; often parents may be repeating the type of child care practiced on them in their childhood.

Physicians, because of their own feelings and their difficuity in playing a role that they find hard to assume, may have great reluctance in believing that parents were guilty of abuse. They may also find it difficult to initiate proper investigation so as to assure adequate management of the case. Above all, the physician's duty and responsibility to the child requires a full evaluation of the problem and a guarantee that the expected repetition of trauma will not be permitted to occur.

4200 E. 9 th Ave., Denver 20 (Dr. Kempe).

\section{REFERENCES}

1. SNEDECOR, S. T., KNAPP, R. E. and WILSON, H. B. Traumatic ossifying periostitis of newborn. Surgery, Gynecology and Obstetrics 61:385-387 (1935).

2. CAFFEY, J. Multiple fractures in long bones of infants suffering from chronic subdural hematoma. American Journal of Roentgenology 56:163-173 (1946).

3. SNEDECOR, S T. and WILSON, H. B. Some obstetrical injuries to long bones. Journal of Bone and Joint Surgery 31A:378-384 (1949).

4. SMITH, M. J. Subdural hematoma with multiple fractures. American Journal of Roentgenology 63:342-344 (1950).

5. FRAUENBERGER, G. S. AND LIS, E. F. Multiple fractures associated with subdural hematoma in infancy. Pediatrics 6:890-892 (1950).

6. BARMEYER, G. H., ALDERSON, L. R. and COX, W. B. Traumatic periostitis in young children. Journal of Pediatrics 38:184-190 (1951).

7. SILVERMAN, F. Roentgen manifestations of unrecognized skeletal trauma in infants. American Journal of Roentgenology 69:413-426 (1953).

8. WOOLLEY. P. V., JR. and EVANS. W. A., JR. Significance of skeletal lesions in infants resembling those of traumatic origin. Journal of the American Medical Association 158:539-543 (1955).

9. BAKWIN, H. Muitiple skeletal lesions in young children due to trauma. Journal of Pediatrics 49:7-15 (1956).

10. CAFFEY, J. Some traumatic lesions in growing bones other than fractures and dislocations: Clinical and radiological features. British Journal of Radiology 30:225-238 (1957).

11. WESTON, W. J. Metaphyseal fractures in infancy. Journal of Bone and Joint Surgery (Brit.) 39B:694-700 (1957).

12. FISHER, S. H. Skeletal manifestations of parent-induced trauma in infants and children. Southern Medical Journal 51:956-960 (1958).

13. MILLER, D. S. Fractures among children. Minnesota Medicine 42:1209-1213; 1414-1425 (1959).

14. SILVER, H. K. and KEMPE, C. H. Problem of parental criminal neglect and severe physical abuse of children. Journal of Diseases of Children 95:528 (1959).

15. ALTMAN, D. H. and SMITH, R. L. Unrecognized trauma in infants and children. Journal of Bone and Joint Surgery 42A:407-413 (1960).

16. ELMER, E. Abused young children seen in hospitals. Social Work 5:98-102 (1960).

17. GWINN, J. L., LEWIN, K. W. and PETERSON, H. G. JR. Roentgenographic manifestations of unsuspected trauma in infancy. Journal of the American Medical Association 176:926-929 (1961).

18. BOARDMAN, H. E. Project to rescue children from inflicted injuries. Social Work 7:43 (1962). 